University of Nebraska - Lincoln

DigitalCommons@University of Nebraska - Lincoln

Si-Hwang Liou Publications

Research Papers in Physics and Astronomy

January 2006

\title{
Structure of $\mathrm{Sc}_{2} \mathrm{O}_{3}$ films epitaxially grown on $\alpha-\mathrm{Al}_{2} \mathrm{O}_{3}(0001)$
}

\author{
A.R. Kortan \\ OFS Laboratories, Murray Hill, New Jersey \\ N. Kopylov \\ OFS Laboratories, Murray Hill, New Jersey \\ J. Kwo \\ National Tsing Hua University, Hsin Chu, Taiwan \\ M. Hong \\ National Tsing Hua University, Hsin Chu, Taiwan \\ C.P. Chen \\ National Tsing Hua University, Hsin Chu, Taiwan \\ See next page for additional authors
}

Follow this and additional works at: https://digitalcommons.unl.edu/physicsliou

Part of the Physics Commons

Kortan, A.R.; Kopylov, N.; Kwo, J.; Hong, M.; Chen, C.P.; Mannaerts, J.P.; and Liou, Sy_Hwang, "Structure of $\mathrm{Sc}_{2} \mathrm{O}_{3}$ films epitaxially grown on $\alpha-\mathrm{Al}_{2} \mathrm{O}_{3}$ (0001)" (2006). Si-Hwang Liou Publications. 74.

https://digitalcommons.unl.edu/physicsliou/74

This Article is brought to you for free and open access by the Research Papers in Physics and Astronomy at DigitalCommons@University of Nebraska - Lincoln. It has been accepted for inclusion in Si-Hwang Liou Publications by an authorized administrator of DigitalCommons@University of Nebraska - Lincoln. 


\section{Authors}

A.R. Kortan, N. Kopylov, J. Kwo, M. Hong, C.P. Chen, J.P. Mannaerts, and Sy_Hwang Liou 


\title{
Structure of $\mathrm{Sc}_{2} \mathrm{O}_{3}$ films epitaxially grown on $\alpha-\mathrm{Al}_{2} \mathrm{O}_{3}(0001)$
}

\author{
A. R. Kortan and N. Kopylov \\ OFS Laboratories, 600 Mountain Avenue, Murray Hill, New Jersey 07974 \\ J. Kwo \\ Department of Physics, National Tsing Hua University, Hsin Chu, Taiwan 30013 \\ M. Hong, ${ }^{\text {a) }}$ C. P. Chen, and J. P. Mannaerts \\ Department of Materials Science and Engineering, National Tsing Hua University, Hsin Chu, Taiwan 30013 \\ S. H. Liou \\ Department of Physics, University of Nebraska, Lincoln, Nebraska 68588
}

(Received 12 August 2005; accepted 8 December 2005; published online 10 January 2006)

\begin{abstract}
The crystal structure of scandium oxide films epitaxially grown on $\alpha-\mathrm{Al}_{2} \mathrm{O}_{3}$ (0001) under an ultrahigh-vacuum is studied by single-crystal $\mathrm{x}$-ray diffraction. The $\mathrm{Sc}_{2} \mathrm{O}_{3}$ film grows in bixbyite phase on the basal (0001) surface of the sapphire substrate with its $\langle 111\rangle$ axis aligned parallel to the substrate normal. In-plane orientation of the film, however, exhibits two distinct growth directions that are defined by the two possible surface orientations of the stepped $\alpha-\mathrm{Al}_{2} \mathrm{O}_{3}$ substrate. The atomic structure of the high-quality epitaxial film is fully relaxed and the film has unusual thickness uniformity. () 2006 American Institute of Physics. [DOI: 10.1063/1.2163989]
\end{abstract}

High- $\kappa$ dielectric oxide films are subjects of intense research, as ever shrinking size of the Si-based electronic devices require new high-performance ultrathin gate oxides with thickness below a nanometer (equivalent thickness of $\mathrm{SiO}_{2}$ ). When the oxide layer thickness approaches a few atomic layers, the dielectric uniformity may be best supported by epitaxial single-crystalline oxide films. Indeed, this was demonstrated in $\mathrm{Gd}_{2} \mathrm{O}_{3}$ films grown on GaAs, which yielded a low interfacial density of states $\left(D_{\text {it }}\right)$ and a very low leakage current density, ${ }^{1}$ better than many amorphous high- $k$ dielectrics on Si. For GaN, the semiconductor of choice for blue lasers and high-power electronic devices, thin single-crystal $\mathrm{Gd}_{2} \mathrm{O}_{3}$ and $\mathrm{Y}_{2} \mathrm{O}_{3}$ films grown epitaxially on GaN give ${ }^{2}$ a low $D_{\mathrm{it}} . \mathrm{Sc}_{2} \mathrm{O}_{3}$ films grown ${ }^{3}$ on GaN have also achieved a low $D_{\text {it }}$, as well as improved the device performance. ${ }^{4}$

As the film thickness decreases, substrate starts playing an important role in determining the crystal structure of the film, as we demonstrated in the hexagonal-close-packed (hcp)-phase $\mathrm{Gd}_{2} \mathrm{O}_{3}$ film growth on $\mathrm{GaN}$. The hcp phase, normally a high-temperature phase, was stabilized by the epitaxial locking to the underlying substrate. In an earlier study, $\mathrm{Sc}_{2} \mathrm{O}_{3}$ was conjectured to grow in a cubic crystalline form on $\mathrm{GaN}$, based on a single broad Bragg peak observed in an x-ray diffraction scan. ${ }^{3}$ In our studies of $\mathrm{Sc}_{2} \mathrm{O}_{3}$ grown on $\mathrm{GaN}$ using electron-beam (e-beam) evaporation techniques in an ultrahigh vacuum (UHV), we found that $\mathrm{Sc}_{2} \mathrm{O}_{3}$ film grows epitaxially in a bixbyite phase on the (0001) surface of the wurzite $\mathrm{GaN}$ substrate with its $\langle 111\rangle$ axis aligned parallel to the substrate normal, determined by both in situ reflection high-energy electron diffraction (RHEED) and x-ray diffraction, in single-crystal geometry setup. ${ }^{5}$

While heteroepitaxial oxide-semiconductor films have been the center of focused research, multilayered heteroepitaxial oxide films have escaped much attention. Multilayered

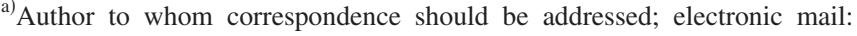
mhong@mx.nthu.edu.tw
}

oxide films may provide an extra degree of freedom in many device designs. Here, we report the heteroepitaxial growth of high-quality $\mathrm{Sc}_{2} \mathrm{O}_{3}$ films on the (0001) basal plane of sapphire $\left(\alpha-\mathrm{Al}_{2} \mathrm{O}_{3}\right)$ substrate. These findings are remarkable in light of the fact that $\mathrm{Sc}_{2} \mathrm{O}_{3}$ and $\alpha-\mathrm{Al}_{2} \mathrm{O}_{3}$ atomic structures are significantly different.

Growth of oxide films was carried out in a UHV chamber by e-beam evaporation of a powder packed $\mathrm{Sc}_{2} \mathrm{O}_{3}$ target. Sapphire $\left(\mathrm{Al}_{2} \mathrm{O}_{3}\right)$ substrates 2 in. in diameter, were heated to over $700{ }^{\circ} \mathrm{C}$ in the UHV chamber to clean the surface, and then the substrate temperature was lowered to $600{ }^{\circ} \mathrm{C}$ for the oxide film growth. RHEED was used to monitor the film growth. Single-crystal x-ray diffraction measurements were carried out on a triple-axis geometry four-circle ganiometer using a $12 \mathrm{~kW}$ rotating anode machine and $\mathrm{Cu} K \alpha$ radiation. A focusing graphite monochromator and a flat graphite analyzer crystal provided a resolution of $0.01 \AA^{-1}$ and $0.005 \AA^{-1}$ for the longitudinal and the transverse directions, respectively, which were chosen intentionally low in order to improve the beam intensity. Most importantly, the triple-axis geometry allowed us to map the true reciprocal space by separately resolving two-theta and theta angular measurements.

A reciprocal space scan along the surface normal is shown in Fig. 1, in which narrow peaks of $\mathrm{Al}_{2} \mathrm{O}_{3}$ (0003), (0006), and (0009) are observed. The indices refer to the hexagonal unit cell. The broader peaks at $31.400^{\circ}$ and $65.387^{\circ}$ match well with (222), and (444) peaks of the $\mathrm{Sc}_{2} \mathrm{O}_{3}$-bixbyite cubic phase, and suggest a lattice constant of $9.869 \AA$ A. A closer look at the $\mathrm{Sc}_{2} \mathrm{O}_{3}$ (222) peak reveals an oscillatory behavior of the intensity as shown in the inset (a) of Fig. 1. The period of this oscillation in real space corresponds to a film thickness of $152 \pm 2 \AA$, and the persistence of these oscillations to high orders indicates a highly uniform film thickness. A dynamic diffraction modeling ${ }^{6}$ with a thickness variation of $2 \AA$ root-mean square as shown in (b) in the inset of Fig. 1, suggests that surface flatness is of the order of few $\AA$. Rounding of the peaks is due to low instrumental 


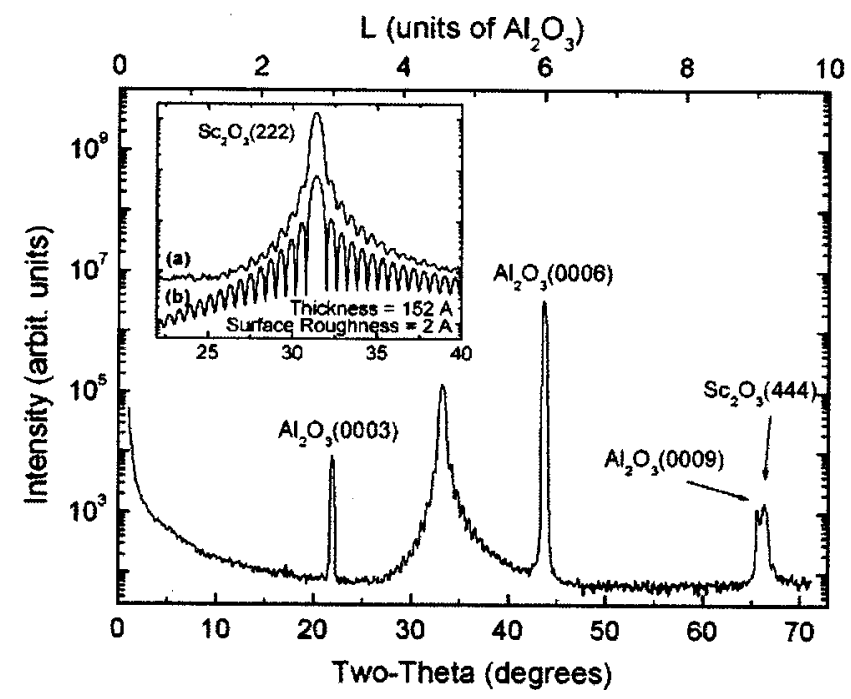

FIG. 1. Single crystal $\mathrm{x}$-ray scans along the surface normal reveal $\alpha$ $\mathrm{Al}_{2} \mathrm{O}_{3}$ substrate and the (222), and (444) peaks of the $\mathrm{Sc}_{2} \mathrm{O}_{3}$-bixbyite cubic phase. The inset shows an expanded view of the $\mathrm{Sc}_{2} \mathrm{O}_{3}(222)$ peak along the surface normal in (a), and the corresponding curve from a dynamical diffraction model (b).

resolution, and high-order peaks are obscured by the noise floor. In Fig. 2(a), the intensity distribution in twodimensional reciprocal space confirms the single crystalline nature of the film. The rocking (theta) scans at the $\mathrm{Al}_{2} \mathrm{O}_{3}$
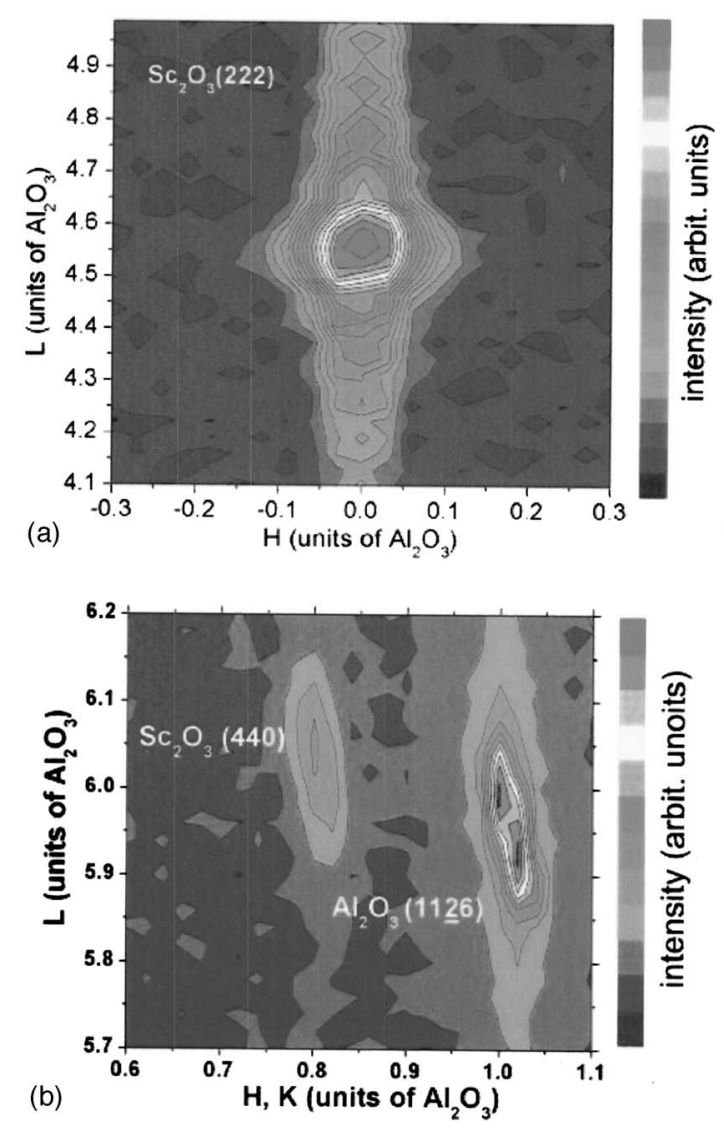

FIG. 2. An area scan about the $\mathrm{Sc}_{2} \mathrm{O}_{3}$ (222) peak (a), in single crystal geometry is shown in the $(\mathrm{H}, 0, \overline{\mathrm{H}}, \mathrm{L})$ plane. Single-crystal $\mathrm{x}$-ray diffraction measurements in the reciprocal space are shown in the plane of the $\mathrm{Al}_{2} \mathrm{O}_{3}$ lattice $(\mathrm{H}, \mathrm{H}, \overline{2} \mathrm{H}, \mathrm{L})$, about the $\mathrm{Al}_{2} \mathrm{O}_{3}(11 \overline{2} 6)$ and $\mathrm{Sc}_{2} \mathrm{O}_{3}(440)$ peaks in (b). [The splitting of the $\mathrm{Al}_{2} \mathrm{O}_{3}$ peak in (b) is an artifact of the two-dimensional scans.] shown with dark triangles in Fig. 3. In order to explain the
Downloaded 18 Oct 2006 to 129.93.16.206. Redistribution subject to AIP license or copyright, see http://apl.aip.org/apl/copyright.jsp

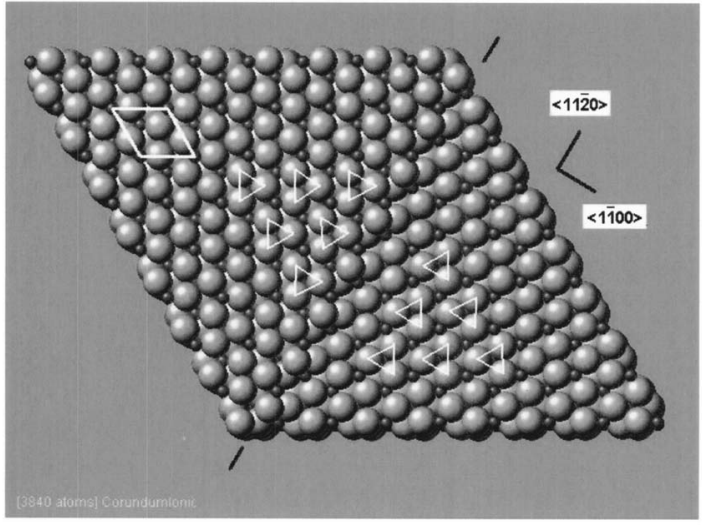

FIG. 3. The low-energy Al-terminated (0001) basal plane of $\alpha-\mathrm{Al}_{2} \mathrm{O}_{3}$ with a step running along the $\langle 11 \overline{2} 0\rangle$ direction is shown. Unit cell is indicated by white lines, $\mathrm{Al}$ atoms by small dark circles and symmetry-equivalent adatom sites are marked by dark triangles. Elemental steps on this surface give rise to a $60^{\circ}$ rotation of adatom site symmetry on the neighboring terraces.

(0006), and the $\mathrm{Sc}_{2} \mathrm{O}_{3}$ (222) peaks, find widths of $0.21^{\circ}$ and $0.29^{\circ}$, respectively, indicating a good crystalline perfection for the thin oxide film.

In order to gain a better understanding of the crystal structure of the film, scans along major zone axes of the substrate $\left(\mathrm{Al}_{2} \mathrm{O}_{3}\right)$ and the bixbyite $\left(\mathrm{Sc}_{2} \mathrm{O}_{3}\right)$ reciprocal space have been carried out. We have found no evidence for diffraction peaks that belonged to other epitaxy-stabilized structures, such as the hexagonal phase (which occurs for the growth of $\mathrm{Gd}_{2} \mathrm{O}_{3}$ on $\mathrm{GaN}$ ) and confirmed that all the observed reflections belonged to the bixbyite structure. Figure 2(b) shows the $\mathrm{x}$-ray intensity distribution in the $(\mathrm{H}, \mathrm{H}, \overline{2} \mathrm{H}, \mathrm{L})$ plane about $\mathrm{Al}_{2} \mathrm{O}_{3}(11 \overline{2} 6)$ and $\mathrm{Sc}_{2} \mathrm{O}_{3}(440)$ peaks. The shape of the oxide film peak is very similar to the substrate peak, indicating that the film does not contain extra defects in addition to that of the substrate.

Phi-angle conical scans about the surface normal $\langle 111\rangle$, for $\mathrm{Sc}_{2} \mathrm{O}_{3}\{440\}$, and the substrate $\mathrm{Al}_{2} \mathrm{O}_{3}\{0,1, \overline{1}, 2\}$ peaks were taken for comparison. These scans are made by tilting the surface normal chi-angle to bring the particular reflections into the scattering plane and measuring intensity along the phi-angle. Substrate $\{0,1, \overline{1}, 2\}$ peaks are strong and sharp $\left(0.29^{\circ}\right.$ width $)$ and are spaced by $120^{\circ}$, consistent with the $\mathrm{R} \overline{3} \mathrm{c}$ symmetry. The $\mathrm{Sc}_{2} \mathrm{O}_{3}\{440\}$ peaks are about $3^{\circ}$ wide and are spaced by $60^{\circ}$. For this layer of reciprocal space, the rotational symmetry about the $\langle 111\rangle$ axis is three fold with $120^{\circ}$ angular spacing. The extra set of peaks is due to a second preferred growth orientation of the film on this substrate surface. This twin growth orientation is also confirmed in other reciprocal space scans. The $\alpha-\mathrm{Al}_{2} \mathrm{O}_{3}$ (0001) surface has a pseudo-six-fold symmetry when only the top layer of atoms are considered, as shown in Fig. 3. It may be natural, therefore, to conclude that the $\langle 111\rangle$ growth axis of the cubic bixbyite phase will have two equivalent in-plane orientations or twins, with its $\mathrm{C}_{3}$ symmetry. The six-fold symmetry of the substrate surface, however, gets reduced to three-fold when we consider the second and third layer of atoms under the surface. An adsorbing atom on the surface would clearly feel the presence of atoms few layers down, and would choose able three-fold sites for the occupation of the adatoms are sites that maximize the cation-cation separation. Such favor- 


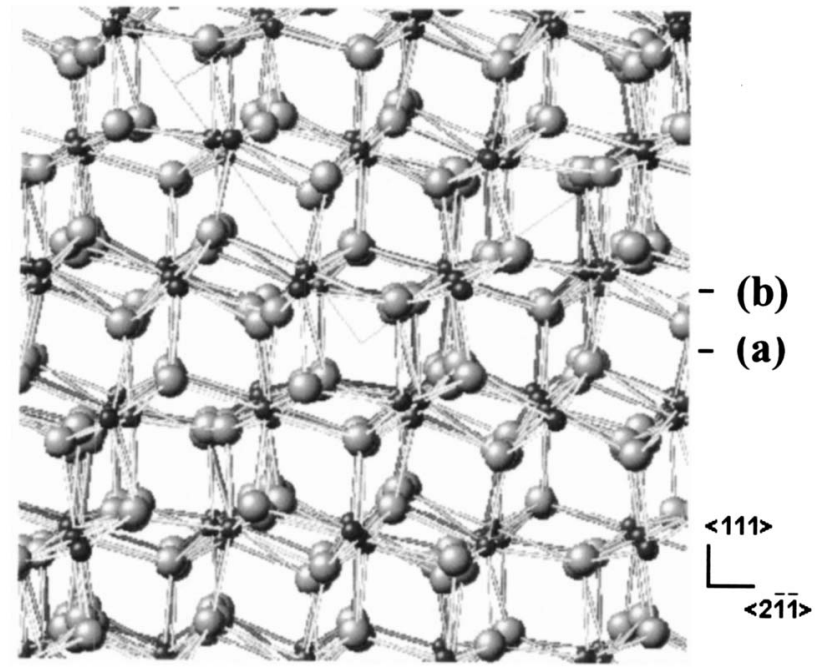

FIG. 4. Side view of the bixbyite $\mathrm{Sc}_{2} \mathrm{O}_{3}$ crystal structure, in the $\langle 111\rangle,\langle 2 \overline{1} \overline{1}\rangle$ plane. The structure consists of bilayers of oxygen separating scandium atoms. Two distinct cuts possible through the structure are shown in (a) and (b).

twinned growth, we must consider film growth on stepped surfaces.

The $\alpha-\mathrm{Al}_{2} \mathrm{O}_{3}$ (0001) is one of most intensively studied surfaces because of its technological importance. Bulk structure consists of distorted hcp packing of oxygen atoms with cations occupying two-thirds of the available sites. The minimum surface energy of (0001) of $3.7 \mathrm{~J} / \mathrm{m}^{2}$ corresponds to the bulk termination with an aluminum top layer. ${ }^{7}$ While every (0001) surface is three-fold symmetric, neighboring minimum-energy surfaces separated by elemental steps are rotated by $60^{\circ}$ with respect to each other. ${ }^{7}$ Figure 3 shows the top view of the two (0001) surfaces separated by a step running along the $\langle 11 \overline{2} 0\rangle$ direction, as also observed experimentally in $\mathrm{MgO}$ growth on $\alpha-\mathrm{Al}_{2} \mathrm{O}_{3}(0001){ }^{8}$ Over large surfaces, where steps can not be avoided, the $\mathrm{Sc}_{2} \mathrm{O}_{3}$ epitaxial films nucleating and growing on terraces separated by steps will therefore grow in two distinct in-plane orientations.

The extreme flatness of the $\mathrm{Sc}_{2} \mathrm{O}_{3}$ epitaxial film suggests a low surface energy, as expected for this densely packed (111) surface. Energetics of the surface structure can be constructed through possible cuts of the bulk crystal structure. Bixbyite is a vacancy ordered derivative of the $\mathrm{CaF}_{2}$ structure, and there are two energetically distinct cuts possible, (a) and (b), as shown in Fig. 4. Since a (b) cut cuts through three bonds per anion compared to an (a) cut with one bond per anion, the low energy surface will be oxygen terminated. This was mentioned by Pauling ${ }^{9}$ in the original discovery of bixbyites where he referred to the (111) basal cleavage resulting from electrically neutral layers of ions - the double layers of octahedra.

Despite significantly different crystal structures of $\mathrm{Sc}_{2} \mathrm{O}_{3}$ and $\alpha-\mathrm{Al}_{2} \mathrm{O}_{3}$, our measurements suggest a sharp abrupt interface formation. In simple terms, this can be understood by an interface formation that is created by bringing the low- energy surfaces of the film and the bulk, or by placing an oxygen-terminated surface on an aluminum-terminated $\alpha$ $\mathrm{Al}_{2} \mathrm{O}_{3}$ (0001) surface. Two structures exhibit matching unit cells at a superlattice distance of $a\left(\mathrm{Al}_{2} \mathrm{O}_{3}\right)_{\text {inplane }} \times 3$ $=14.28 \AA$ and $a\left(\mathrm{Sc}_{2} \mathrm{O}_{3}\right)_{\text {inplane }}=13.96 \AA$, with a lattice mismatch of $2.2 \%$, and a fully relaxed epilayer as determined experimentally. At the interface, we expect some atomic rearrangement that is configurationally optimized to both structures. The great dissimilarity between the two layers may be the key to an abrupt interface, and localize misfit defects to the narrow region.

Even with their similar chemistry, it is surprising that the film and the substrate cations with surrounding oxygens do not share the same local symmetry across the interface. Note that there is a $30^{\circ}$ rotation between the densely packed planes of the film and the substrate. This must be the key to satisfying the chemical constrains across the interface, while simultaneously satisfying the epitaxial conditions over a superlattice length.

In conclusion, we report high-quality heteroepitaxial film growth of binary oxide $\mathrm{Sc}_{2} \mathrm{O}_{3}$ on the $\alpha-\mathrm{Al}_{2} \mathrm{O}_{3}$ (0001) substrate. The film with $2.2 \%$ lattice mismatch is fully relaxed and exhibits remarkable thickness uniformity. Epitaxial lattice matching conditions are met over a superlattice length of three times the lattice constant of the substrate. It is likely that most of the misfit-related defects are confined to a narrow region near the interface, not extending into the film to destroy the crystalline order of the $\mathrm{Sc}_{2} \mathrm{O}_{3}$ epitaxial film. The film growth takes place with two distinct, twinned in-plane orientations, characteristic of the stepped $\alpha-\mathrm{Al}_{2} \mathrm{O}_{3}$ (0001) substrate surface that exhibits $60^{\circ}$ rotated three-fold surface symmetries on neighboring terraces separated by steps. The film twinning can be eliminated on short-length scales where a single terrace width matches the ever-shrinking device size.

The authors wish to thank the Department of Natural Sciences at the National Science Council, and the Center for Nano-Science and Technology, University System of Taiwan, R.O.C. for supporting this work.

${ }^{1}$ M. Hong, J. Kwo, A. R. Kortan, J. P. Mannaerts, and A. M. Sergent, Science 283, 1897 (1999).

${ }^{2}$ M. Hong, A. R. Kortan, J. Kwo, J. P. Mannaerts, C. M. Lee, and J. I. Chyi, Proceedings of 2000 IEEE International Symposium on Compound Semiconductors (IEEE, New York, 2000), p. 495.

${ }^{3}$ B. P. Gila, J. W. Johnson, R. Mehandru, B. Luo, A. H. Onstine, K. K. Allums, V. Krishnamoorthy, S. Bates, C. R. Abernathy, F. Ren, and S. J. Pearton, Phys. Status Solidi A 188, 239 (2001).

${ }^{4}$ B. Luo, J. W. Johnson, J. Kim, R. M. Mehandru, F. Ren, B. P. Gila, A. H. Onstine, C. R. Abernathy, S. J. Pearton, A. G. Baca, R. D. Briggs, R. J. Shul, C. Monier, and J. Han, Appl. Phys. Lett. 80, 1661 (2002).

${ }^{5}$ A. R. Kortan, M. Hong, J. Kwo, H. M. Ng, and J. P. Mannaerts (unpublished).

${ }^{6}$ S. A. Stepanov, Crystallogr. Rep. 39, $182 \quad$ (1994); 〈http:// sergey.gmca.aps.anl.gov/gid_sl.html $>$.

${ }^{7}$ J. Guo, H. L. M. Chang, and D. J. Lam, Appl. Phys. Lett. 61, 3116 (1992).

${ }^{8}$ D. X. Li, P. Pirouz, A. H. Heuer, S. Yadavalli, and C. P. Flynn, Philos. Mag. A 65, 403 (1992).

${ }^{9}$ L. Pauling, Z. Kristallogr. 69, 415 (1929). 